\title{
PENYIRAMAN TANAMAN OTOMATIS MENGGUNAKAN SENSOR SOIL MOISTURE DAN SENSOR SUHU
}

\author{
Nuraida Latif \\ Progam Studi Teknik Informatika, STMIK AKBA \\ Jalan Perintis Kemerdekaan, Makassar, Indonesia \\ nuraida@akba.ac.id
}

\begin{abstract}
ABSTRAK
Penelitian ini bertujuan untuk merancang sistem penyiraman tanaman secara otomatis menggunakan sensor soil moisture dan sensor suhu. Metode penelitian yang digunakan yaitu penelitian kuantitatif dengan teknik pengumpulan data berupa studi pustaka. Selanjutnya pada metode pengujian yang digunakan adalah blackbox dengan menguji sensor terhadap suhu dan kelembaban yang mewakili peralatan listrik. Hasil penelitian ini menunjukkan bahwa mplementasi mikrokontroller sebagai komunikasi alat, hubungan antar komponen tersebut melalui sensor moisture dan sensor DHT11. LCD sebagai pembaca suhu dan kelembaban.
\end{abstract}

Kata Kunci : Mikrokontroller Arduino, Sensor Soil Moisture, Sensor DHT11, Driver L298N.

\begin{abstract}
This study aims to design an automatic watering system for plants using a soil moisture sensor and a temperature sensor. The research method used is quantitative research with data collection techniques in the form of literature study. Furthermore, the testing method used is a blackbox by testing the sensor of temperature and humidity representing electrical equipment. The results of this study indicate that the implementation of the microcontroller as a communication tool, the relationship between these components through a moisture sensor and DHT11 sensor. LCD as a reader of temperature and humidity.
\end{abstract}

Keywords : Arduino Microcontroller, Soil Moisture Sensor, DHT11 Sensor, Driver L298N. 


\section{PENDAhULUAN}

Sebagian petani di Indonesia masih tergantung dengan musim hujan untuk bercocok tanam. Hal ini menyebabkan produksi hasil pertanian tidak bisa stabil setiap saat. Pada musim kemarau harga-harga hasil pertanian bisa mengalami kenaikan yang sangat signifikan karena produksinya yang sedikit. Sedangkan di saat musim hujan produksi melimpah sehingga harganya murah bahkan sampai busuk tidak laku dijual kepasar karena stoknya masih berlimpah. Hal inilah yang menyebabkan petani banyak mengalami kerugian dan akhirnya frustasi karena kecewa. Saat musim kemarau para petani yang ingin tetap bercocok tanam harus mengeluarkan tenaga dan biaya ekstra melakukan penyiraman secara manual agar tanamannya biasa tumbuh subur dan bisa panen.

Dari waktu ke waktu kita dihadapkan pada perkembangan teknologi yang begitu pesat, sehingga membuat pekerjaan manusia semakin mudah. Karena itu peneliti berusaha untuk membuat sistem penyiraman tanaman secara otomatis. Pada penelitian ini menggunakan sensor soil moisture / sensor kelembaban, sensor suhu dan Arduino uno sebagai kendali dan kontrol utama dalam alat tersebut. Alat ini berfungsi untuk menyiram tanaman secara otomatis menggunakan sensor soil suhu dan arduino uno. Berdasarkan sensor soil moisturetanah yang sudah di set sesuai kebutuhan tanaman, alat ini juga dilengkapi LCD (Linquid Cristal Display) yang dapat menampilkan kondisi tanah, apakah lembab atau kering, sesuai dengan pembacaan dari sensor soil moisture dan sensor suhu dalam bentuk nilai pada LCD, mengukur kecepatan air dan telegram sebagai alat untuk menampilkan informasi kelembaban dan PH tanah. Alat ini juga dilengkapi dengan pompa air sebagai media penyiraman. Alat ini sangat bermanfaat bagi manusia sekarang ini, karena dengan adanya alat ini tidak perlu lagi menyiram tanaman secara manual setiap harinya, untuk itu alat ini bisa diaplikasikan pada manusia yang suka menanam di dalam ruangan atau menanam di kebun kecil di depan teras rumah dan di tempat lain nya yang bersifat tertutup.

Penelitian sebelumnya tentang penyiraman otomatis pada tanaman yang berbasis arduino uno menggunakan sensor kelembaban tanah menggunakan sensor YL-69 sangat sensitive terhadap perubahan lingkungan dikarenakan bahan pada YL dilapisi dengan bahan anti karatMenurut penelitian yang dilakukan Naibaho (2017), Sedangkan penelitian yang dilakukan Waworundeng (2017), Perancangan Alat Penyiram Tanaman Otomatis berbasis Sensor dan Mikrokontroller hasil penelitian Alat dirancang dengan menggunakan komponen seperti mikrokontroller, sensor kelembaban tanah, relay dan solenoid valve. Sensor melakukan fungsi pendeteksian kelembaban tanah dan mengirimkan sinyal ke mikrokontroller yang mengaktifkan relay dan solenoid valve untuk mengalirkan air jika kondisi tanah kering. Namun mempunyai kekurangan yang tidak bisa dipantau dari jarak jauh. Dan penelitian yang dilakukan olehWakur
(2015) Alat Penyiraman Tanaman Otomatis menggunakan Arduino uno dengan menggunakan Sistem dapat menyiram air kepada tanaman cabai apabila kelembaban tanah dibawah 300 ph kekurangannya tidak menggunakan sensor suhu.Dengan latar belakang ini maka akan dirancangkan sebuah alat PENYIRAMAN TANAMAN OTOMATIS MENGUNAKAN SENSOR SOIL MOISTURE DAN SENSOR SUHU kemudian diproses oleh arduino uno dan diinstruksikan kepada LCD untuk menampilkan nilai kelembaban tanah dan suhu.

\section{TINJAUAN PUSTAKA}

\subsection{Sensor Moisture}

Sensor Soil moisture merupakan sensor yang mampu mendeteksi intensitas air di dalam tanah (moisture). Sensor ini terdiri dua probe untuk melewatkan arus melalui tanah, kemudian membaca resistansinya untuk mendapatkan nilai tingkat kelembaban. Semakin banyak air membuat tanah lebih mudah menghantarkan listrik (resistansi kecil), sedangkan tanah yang kering sangat sulit menghantarkan listrik (resistansi besar). Kedua problem ini merupakan media yang akan menghantarkan tegangan analog yang nilainya relatif kecil. Tegangan ini nantinya akan diubah menjadi tegangan digital untuk diproses ke dalam mikrokontroller (Naibaho).

\subsection{Sensor Suhu DHT11}

DHT11 adalah sensor digital yang dapat mengukur suhu dan kelembaban udara di sekitarnya. Sensor ini sangat mudah digunakan Bersama dengan Arduino.Memiliki tingkat stabilitas yang sangat baik serta fitur kalibrasi yang sangat akurat. Koefisien kalibrasi disimpan dalam OTP program memory, sehingga ketika internal sensor mendeteksi sesuatu, maka module ini menyertakan koefisien tersebut dalam kalkulasinya, DHT11 ini termasuk sensor yang memiliki kualitas terbaik, dinilai dari respon, pembacaan data yang cepat, dan kemampuan antiinterference. Ukurannya yang kecil, dan dengan transmisi sinyal hingga 20 meter dengan spesifikasi digital interfacing system membuat produk ini cocok digunakan untuk banyak aplikasi-aplikasi pengukuran suhu dan kelembaban.Konsumsi daya DHT11 adalah cukup rendah, $5 \mathrm{~V}$ power supply tegangan dan rata-rata maksimum saat ini sekitar $0.5 \mathrm{~mA}$ (Eriyadi dan Nugroho).

\section{$2.3 L C D$}

Liquid Crystal Display (LCD) adalah komponen yang dapat menampilkan tulisan.Salah satu jenisnya memiliki dua baris dengan setiap baris terdiri LCD seperti itu biasa disebut LCD 16×2 (Kadir).

\subsection{Arduino Uno}


Jurnal Ilmiah Ilmu Komputer Vol. 7, No. 1, April 2021

Fakultas Ilmu Komputer

Universitas AL Asyariah Mandar

Arduino adalah sebuah platform elektronik yang bersifat open source serta mudah digunakan. Hal tersebut ditunjukkan agar siapapun dapat membuat proyek interaktif dengan mudah dan menarik. Arduino uno merupakan papan sirkuit berbasis mikrokontroller ATmega328. ATmega 328 adalah chip mikrokontroller 8-bit berbasis AVR-RISC buatan Atmel yang memiliki 32 KB memori ISP flash dengan kemampuan baca-tulis (read/write), $1 \mathrm{~KB}$ EEPROM, 2 KB SRAM dan karena kapasitas memori Flash sebesar $32 \mathrm{~KB}$ inilah kemudian chip ini diberi nama ATmega328 (Wicaksono dan Hidayat).

\subsection{Selada}

Selada merupakan salah satu jenis tanaman sayuran yang dikonsumsi daunnya selada akan terus meningkat sejalan dengan peningkatan jumlah penduduk, peningkatan pendidikan masyarakat, peningkatan pendapatan dan kesejahteraan masyarakat, dan peningkatan kesukaan masyarakat terhadap selada. Selada juga merupakan salah satu sayuran yang banyak dibudidayakan dengan sistem aeroponik, variabel utama yang harus dikendalikan adalah suhu dan kelembaban udara dimana variabel tersebut merupakan faktor pendukung utama dalam cocok tanam aeroponik, pertumbuhan selada akan optimal pada kisaran suhu udara $25{ }^{\circ} \mathrm{C}$ sampai $28{ }^{\circ} \mathrm{C}$ dan kelembaban berkisar antara $65 \%$ sampai $78 \%$ (Sariayu,2017).

\section{METODE YANG DIUSULKAN}

\subsection{Teknik Pengumpulan Data}

Tahap pengumpulan data dengan cara studi pustaka dilakukan dengan cara mencari referensi-referensi yang sesuai dengan objek yang akan diteliti. Dengan metode studi pustaka ini, dilakukan pengumpulan data dan informasi dengan mencari, membaca, mencatat intisari dan mempelajari buku-buku, referensi, jurnal yang relevan, situs-situs internet serta tinjauan pustaka yang berkenaan dengan topic yang dapat dijadikan acuan pembahasan dalam penyusunan laporan penelitian ini. Buku-buku dan data-data tersebut dapat dilihat pada daftar pustaka.

\subsection{Metode Perancangan System}

\subsubsection{Perancangan Sistem}

Dalam perancangan Sistem Penyiraman Otomatis yang akan dirancang ini adalah sebuah penyiraman otomatis yang dikendalikan secara otomatis melalui arduino uno. Dibawah merupakan proses yang akandilakukan sistem secara umum. Selanjutnya mikrokontroller arduino akan membaca informasi yang diberikan modul LCD dan Telegram mengolah informasi tersebut untuk ditampilkan. Setelah mengolah informasi, mikrokontroller akan menjalankan Sensor, dan relay sesuai informasi yaitu penyiraman tanaman secara otomatis.Sinyal.

Sistem otomatis yang dirancang mampu menyiram tanaman. Dalam sistem ini, sensor akan membaca kelembaban tanah dan suhu pada ruangan. Data yang dibaca berupa data yang dikirim ke mikrokontroller arduino uno. Data serial tersebut diterjemahkan oleh mikrokontroller arduino uno menjadi data paralel. Data paralel yang dihasilkan oleh mikrokontoller arduino uno diteruskan ke Driver L298N melalui indikator LED yang berfungsi untuk memastikan apabila pompa dan kipas hidup, begitu juga sebaliknya. Kemudian Driver L298N akan meneruskan data yang digunakan untuk menghidupkan atau mematikan pompa dan kipas. Berikut adalah flowchart pada sistem baru seperti gambar 1.

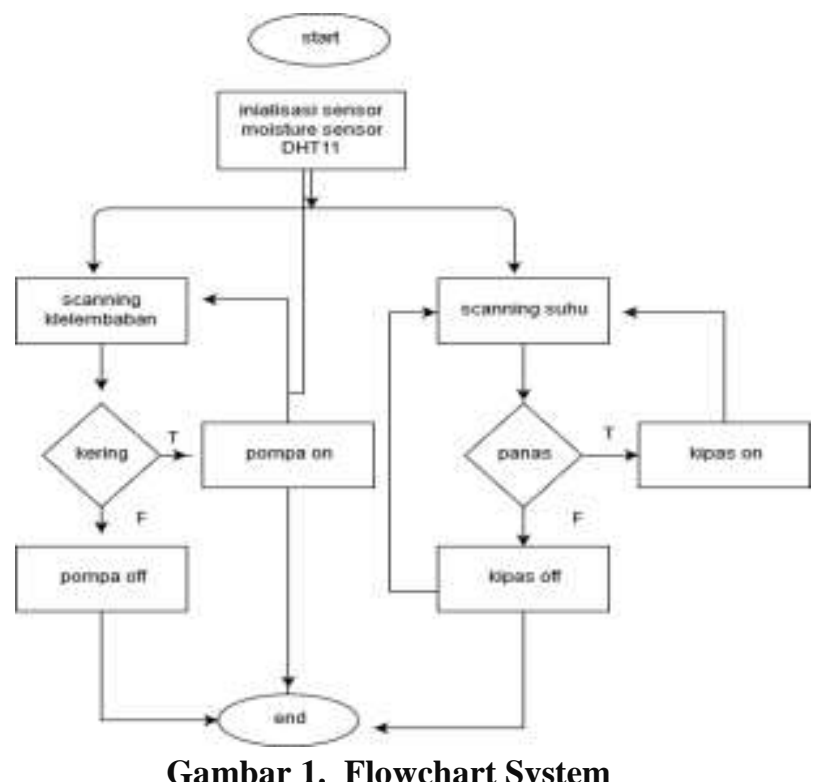

\subsubsection{Perancangan Perangkat Keras}

Perancangan perangkat keras merupakan rancangan atau rangkaian dari alat yang digunakan untuk membangun prototipe Sistem Penyiraman Tanaman Otomatis Menggunakan Sensor Soil moisture.

\subsubsection{Perancangan perangkat lunak}

Pada sistem ini, perancangan perangkat lunak dapat dibedakan menjadi dua bagian yaitu perancangan perangkat lunak pada modul pengendali utama (Papan Mikrokontroller Arduino uno) dan perancangan perangkat lunak penyiraman otomatis menggunakan telegram sebagai rancangan interface.Perancangan perangkat lunak pada arduino sebelum ketahap berikutnya, maka terlebih dahulu dibuatlah flowchart proses upload kode program atau sketch ke papan arduino, dengan flowchart seperti pada gambar 2 .

\subsubsection{Desain Sistem Yang Diusulkan}


Jurnal Ilmiah Ilmu Komputer Vol. 7, No. 1, April 2021

Fakultas Ilmu Komputer

Universitas AL Asyariah Mandar

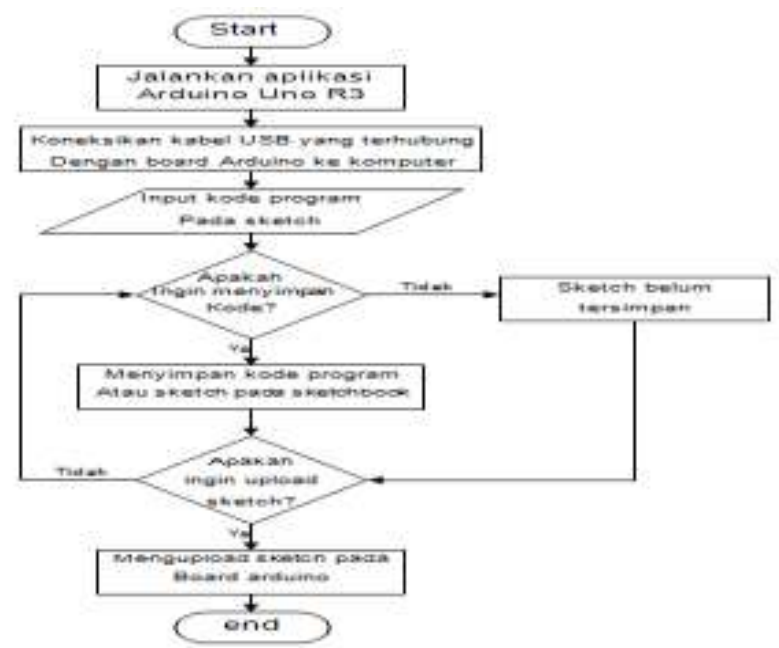

Gambar 2. Flowchart Proses Upload Kode Program

\section{HASIL PENELITIAN}

\subsection{Hasil perancangan}

a. Board arduino

Pada board arduino uno ini terdapat pada rangkaian minimum system untuk berbasis chip Atmega2560. Disebut sebagai papan pengembang karena board ini berfungsi sebagai prototype sirkuit mikrokontroller. Adapun board arduino seperti gambar 3.

\begin{tabular}{|c|c|}
\hline Sebelum & Sesudah \\
\hline & \\
\hline
\end{tabular}

Gambar 3. Board Arduino Uno

b. Sensor soil moisture

Sensor moisture berfungsi untuk mengukur kelembaban pada tanah. Adapun seperti gambar 4.

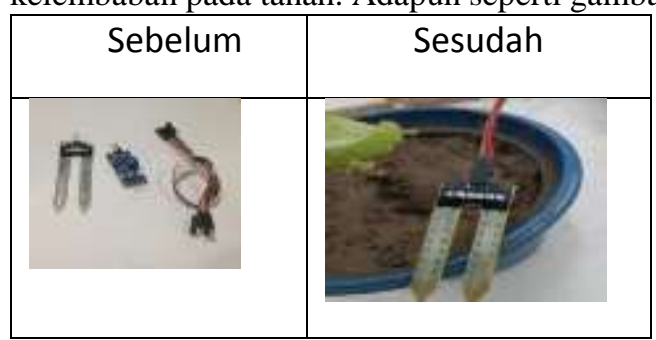

Gambar 4 Sensosr Soil Moisture

\section{c. Sensor DHT11}

Berfungsi untuk mengukur suhu pada ruangan $24^{\circ} \mathrm{C}-28^{\circ} \mathrm{C}$ derajat celcius seperti gambar 5 Gambar 5. Sensosr DHT11

\begin{tabular}{|c|c|}
\hline Sebelum & Sesudah \\
\hline & \\
\hline
\end{tabular}

Gambar 5 Sensor DHT 11

\section{d. $\mathrm{L} 298 \mathrm{~N}$}

Suatu perangkat elektronika yang memberikan arus kepada pompa, kipas dan memberikan output yang lebih tinggi yang digunakan untuk mengidupkan pompa dan kipas. Seperti gambar 6.

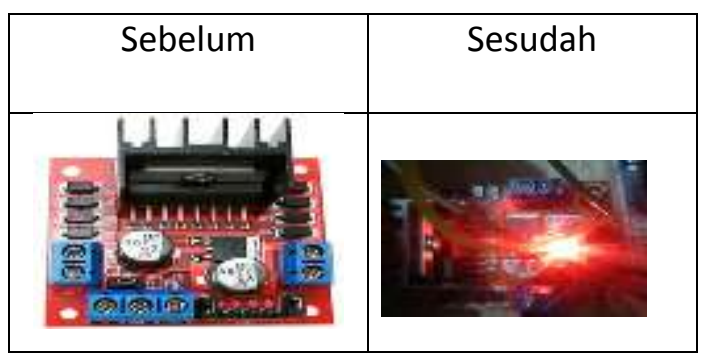

Gambar 6. L298N

e. Pompa

Berfungsi sebagai media penyiram tanaman ketika tanah ada pada kelembaban $>79^{\circ} \mathrm{C}$. Seperti gambar 7

\begin{tabular}{|l|l|}
\hline Sebelum & Sesudah \\
\hline
\end{tabular}

Gambar 7. Pompa

f. Kipas

Berfungsi pada saat suhu dibawah 26 derajat maka kipas akan hidup. Seperti gambar 8

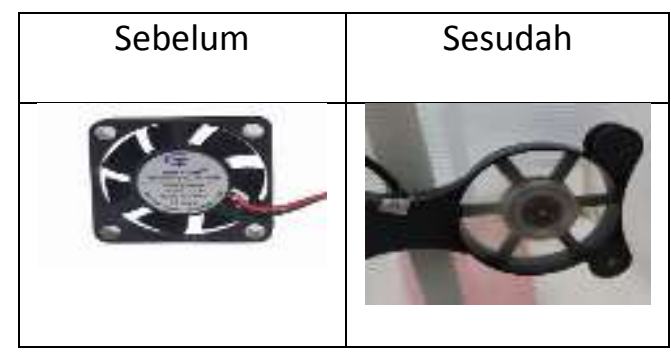

Gambar 8. Kipas

g. LCD

Berfungsi untuk menampilkan suhu dan kelembaban. Seperti gambar 9 
Universitas AL Asyariah Mandar

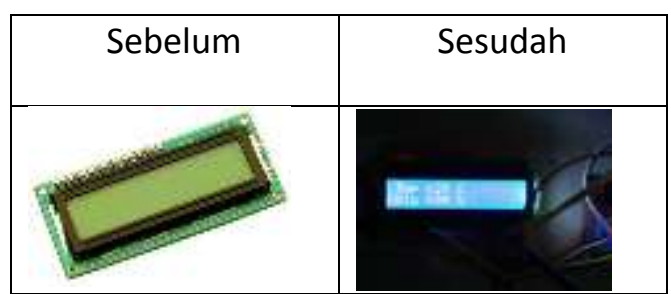

Gambar 9. LCD

\subsection{Pembahasan}

Pengujian yang dilakukan dimaksudkan untuk memberikan apakah alat yang dibuat dapat berjalan dengan baik atau tidak, pengujian terlebih dahulu dilakukan secara terpisah pada masing masing unit dan kemudian dilakukan pengujian ke dalam system yang telah di rancang.

a) Pengujian pertama yang di lakukan adalah pembacaan port pada arduino ke komputer, tujuan dari pembacaan port pada komputer adalah untuk menentukan port yang bias digunakan pada komputer. Apabila port COM \& LPT ada di device maneger untuk menandahkan bahwa arduino sudah siap di gunakan.

b) Pengujian kedua yaitu komunikasi antara arduino uno, sensor soil moisture dan sensor DHT11.

c) Pengujian ketiga yaitu testing pada saat sensor moisture dan sensor DHT11 menerima perintah diteruskan ke arduino selanjutnya arduino memberikan perintah Driver L298N sehinga pompa dan kipas dapat menyiram dan mengetahui suhu ruang dengan baik.

\section{KESIMPULAN}

Berdasarkan hasil perancangan dan pembahasan dari Penyiraman Tanaman Otomatis Mengunakan Sensor Soil moisture, dapat disimpulkan bahwa:

1. Perancangan sistem otomatis ini dirangkai dengan menggunakan perangkat-perangkat pendukung seperi arduino, driver, LCD, sensor moisure, sensor DHT11 sebagai komponen utama dalam membangun sistem ini.

2. Implementasi mikrokontroller sebagai komunikasi alat,hubungan antar komponen tersebut melalui sensor moisture dan sensor DHT11. LCD sebagai pembaca suhu dan kelembaban.

\section{Daftar Pustaka}

[1] Adriansyah, Andi dan Oka Hidyatama .2013. Rancang Bangun Prototipe Elevator Menggunakan Microcontroller Arduino Atmega 328p.

[2] Ajo, Rifaldi. 2018 .Arsitektur Cloud Smart Class Pengontrolan Lampu Otomatis Berbasis Raspberry PI, Passive Infrared dan Lihgt Dependent Resistor

[3] Eriyadi, Nugroho. 2018. Prototype Sistem Penyiram Tanaman Otomatis Berbasis Suhu Udara Dan Kelembaban Tanah.

[4] Irwansyah, Muhammad dan Didi Istardi. 2013. Pompa Air Aquarium Menggunakan Solar Panel.
[5] Kadir, Abdul. 2013. Panduan Praktis Mempelajari Aplikasi Mikrokontroller dan Pemrograman Menggunakan Arduino.

[6] Kendek, Allo. 2013. Rancang Bangun Alat Ukur Temperatur Untuk Mengukur Selisih Dua

[7] Naibaho, Indra batara. 2017. Penyiraman otomatis Pada Tanaman berbasis Arduino.

[8] Sariayu, Martta vira. 2017. Pengendali Suhu Dan Kelembaban Pada Tanaman Selada (Lactuca Sativa L) Dengan Sistem Aeroponik Berbasis Arduino uno R3,

[9] Susanto, Azhar. 2013. Sistem Informasi Akuntansi, Struktur Pengendalian Resiko Pengembangan, Edisi Perdana, Lingga Jaya, Bandung.

[10] Triatmaja, Arif Tri. 2018. Penerapan Sistem Otomatis Administrasi Untuk Meningkatkan Efektivitas Dan Efisiensi Kerja Di Bidang Pendapatan dinas Perdagangan Kota Surakarta.

[11] Wakur. 2015. Alat penyiraman otomatis menggunakan Arduino uno,

[12] Wicaksono Mochammad fajar dan Hidayat. 2017. Mudah Belajar Mikrokontroller Arduino, Informatika Bandung. 